\title{
Influence of prosthesis-patient mismatch on exercise-induced arrhythmias: A further aspect after aortic valve replacement
}

\author{
Vito Antonio Mannacio, MD, Vincenzo De Amicis, MD, Luigi Di Tommaso, MD, Francesco Iorio, MD \\ and Carlo Vosa, MD
}

\begin{abstract}
Objectives: The influence of prosthesis-patient mismatch on outcome after aortic valve replacement is controversial. This study analyzed the impact of prosthesis-patient mismatch on survival, the extent of left ventricular mass, and physical capacity after replacement with a small-size prosthesis.
\end{abstract}

\begin{abstract}
Patients and Methods: A total of 157 patients who underwent valve replacement for pure aortic stenosis were reviewed. Late mortality, morbidity, left ventricular mass regression, transprosthetic gradient at rest and after exercise, exercise capacity, and occurrence of arrhythmias were evaluated.

Results: Prosthesis-patient mismatch, defined as an indexed effective orifice area of $0.75 \mathrm{~cm}^{2} / \mathrm{m}^{2}$ or more, occurred in $96(61.1 \%)$ patients and had no significant impact on early and late mortality. The only independent predictor of mortality was age greater than 65 years. At follow-up, multivariate analysis of prosthetic gradient at rest of $35 \mathrm{~mm} \mathrm{Hg}$ end exercise capacity or more revealed that both these evidences were associated with high left ventricular mass $(P<.001)$, female gender $(P<.001)$, and follow-up time $(P<.001)$. Arrhythmias occurred during exercise in $34.1 \%$ of patients (40/117). Multivariate analysis of occurrence of arrhythmias revealed that they were associated with high mean transprosthetic gradients: values of $50 \mathrm{~mm} \mathrm{Hg}$ or more during exercise had $95 \%$ sensitivity and $72 \%$ specificity for predicting arrhythmias.
\end{abstract}

Conclusion: Prosthesis-patient mismatch failed to demonstrate any significant impact on early and late mortality and morbidity and in left ventricular mass regression. High transprosthetic gradients influence exercise capacity and occurrence of arrhythmias.

Aortic valve replacement (AVR) is the treatment of choice for patients with severe aortic stenosis (AS). Despite an increasing number of high-risk patients, mortality and morbidity of surgical treatment remain low. Complete relief of transvalvular gradient is the goal of surgery. Often, a prosthesis is implanted that is too small for the patient's need.

Prosthesis-patient mismatch (PPM), as first described by Rahimtoola ${ }^{1}$ in 1978 , occurs when the effective orifice area (EOA) of the prosthesis is too small in relation to patient body size and thus can result in persistent left ventricular (LV) outflow tract obstruction. The impact of PPM on hemodynamic status, patient survival, and morbidity has recently been questioned. ${ }^{2-4}$ Several reports, involving a large number of patients, concluded that PPM can be observed in $19 \%$ to $70 \%$ of patients undergoing $\mathrm{AVR}^{5,6}$ and that the valve size may have no effect on early and late clinical results. ${ }^{7-10}$ The aim of this study was to evaluate PPM occurrence in patients who underwent AVR for pure AS with size 19- or 21-mm

From the Department of Cardiac Surgery, University of Naples Federico II, Naples, Italy.

Received for publication July 30, 2008; revisions received Dec 3, 2008; accepted for publication Jan 19, 2009; available ahead of print April 9, 2009.

Address for reprints: Vito Antonio Mannacio, MD, Via S. Domenico 62, 80127 Naples, Italy. (E-mail: vitomannacio2@libero.it).

J Thorac Cardiovasc Surg 2009;138:632-8

$0022-5223 / \$ 36.00$

Copyright (c) 2009 by The American Association for Thoracic Surgery

doi:10.1016/j.jtcvs.2009.01.009 prostheses and its influence on LV mass (LVM) regression, transprosthetic gradients, exercise capacity, and arrhythmia occurrence with regard to late mortality and morbidity.

\section{MATERIAL AND METHODS Definition of PPM}

PPM occurs when the size of an artificial valve is inadequate for the recipient. ${ }^{1,11}$ As previously reported, PPM can be predicted by calculating the projected indexed EOA $(\mathrm{EOAi})^{4,12,13}$ derived from the published normal values of EOA for each model and size of prosthesis ${ }^{2,6,12,14-17}$ divided by body surface area (BSA). PPM was previously defined as not clinically significant (ie, mild or no PPM) if EOA was greater than $0.85 \mathrm{~cm} / \mathrm{m}^{2}$, as moderate if was greater than $0.65 \mathrm{~cm} / \mathrm{m}^{2}$ and $0.85 \mathrm{~cm} / \mathrm{m}^{2}$ or less, and severe if was $0.65 \mathrm{~cm}^{2} / \mathrm{m}^{2}$ or less. ${ }^{6,18}$ In this present study, we defined PPM as EOAi of $0.75 \mathrm{~cm}^{2} / \mathrm{m}^{2}$ or less. The selection of this value was based primarily on results of previous studies. ${ }^{2,19}$ In addition, we did a preliminary analysis that confirmed that this cutoff value provides the best compromise between sensitivity and specificity in the aim of this study end point. ${ }^{2,18,19}$

\section{Study Population}

This retrospective study was conducted at a single cardiac surgery center. The group comprised 157 patients who underwent isolated AVR for pure AS between January 1997 and December 2002. Sixty-nine (43.9\%) received a $19-\mathrm{mm}$ prosthesis and $88(56.1 \%)$ a $21-\mathrm{mm}$ prosthesis. Mean age was $66.7 \pm 8.7$ years. A bioprosthesis was implanted in $73(46.5 \%)$ patients and a mechanical valve in $84(53.5 \%)$. The choice was based on the patient's age, history of thomboembolism or bleeding disorders, liver disease, and preference of the patient or cardiologist. Coronary angiograms were evaluated in all patients before surgery. To obtain a study population as homogeneous as possible and to avoid any confounding interference on 

Abbreviations and Acronyms
AS = aortic stenosis
AVR $=$ aortic valve replacement
BSA = body surface area
CI = confidence intervals
$\mathrm{EOA}=$ effective orifice area
EOAi $=$ indexed effective orifice area
ILVM $=$ indexed left ventricular mass
$\mathrm{LV}=$ left ventricular
$\mathrm{LVM}=$ left ventricular mass
MPG = mean prosthetic gradient
$\mathrm{OR}=$ odds ratio
PEC = predicted maximum exercise capacity
PPM $=$ prosthesis-patient mismatch

results, we used the following exclusion criteria: previous cardiac surgery, associated aortic diseases, simultaneous mitral or tricuspid replacement or repair, previous myocardial infarction, evidence of coronary lesions, poor cardiac function as indicated by ejection fraction less than $40 \%$, and chronic atrial fibrillation. The cutoff point was 75 years for aged patients. Preoperative and surgical variables are summarized in Table 1 .

All patients had echocardiographic evaluation before surgery by an experienced echocardiographer and were followed up with serial transthoracic evaluations before discharge, 3 to 6 months after the operation, and annually thereafter. LV function was evaluated by the ejection fraction calculated by the Simpson rule. The LVM was assessed by the following formula: LVM $=1.04([\mathrm{LVIDd}+\mathrm{IVSD}+\mathrm{LPWDd}] 3-[$ LVIDd $] 3)-13.6$, and was normalized to BSA. (LVIDd $=$ LV internal diameter in diastole; IVSD $=$ intraventricular septal diameter; LPWDd $=$ left posterior wall diameter in diastole.) LV hypertrophy was defined as an indexed LV mass (ILVM) more than 130 $\mathrm{g} / \mathrm{m}^{2}$ in men and more than $100 \mathrm{~g} / \mathrm{m}^{2}$ in women. ${ }^{20}$ The peak and mean prosthetic gradients (MPGs) were calculated from continuous-wave Doppler measurements using the modified Bernoulli equation. The measurements were made according to the recommendations of the American Society of Echography. ${ }^{21}$

Follow-up ranged from 58 to 129 months (mean $83.8 \pm 31.9$ ). Sixty-four percent $(82 / 128)$ of patients had a follow-up of more than 7 years. Scheduled follow-up consisted in clinical interview and electrocardiographic and echocardiographic evaluation at rest and after exercise.

Stress test was performed in all patients 5 days after therapy withdrawal. The bicycle exercise test was conducted according to a standard protocol starting from a workload of $25 \mathrm{~W}$ and increased by $25 \mathrm{~W}$ at 2-minute intervals. Data on atrial and ventricular arrhythmias were recorded during each stage of exercise and during the recovery period. The reference workload for healthy individuals was $2.5 \mathrm{~W} / \mathrm{kg}$ in women and $3.0 \mathrm{~W} / \mathrm{kg}$ in men between 21 and 30 years, minus $10 \%$ for each decade. This target exercise was calculated for each patient. The achieved maximum workload was registered as percentage of age, sex, weight-predicted maximum exercise capacity (PEC). Tests were limited by symptoms, blood pressure higher than 200/100 mm $\mathrm{Hg}$, arrhythmias, and exhaustion or achievement of $100 \%$ of age, sex, and weight PEC. The recording of Doppler signals was started after 90 seconds, with the patients exercising in the supine position. Arrhythmias were assessed as reported by the American College of Cardiology/American Heart Association. ${ }^{22}$ For this present study, only ventricular arrhythmias were considered and were classified as reported by Frolkis and associates ${ }^{23}$ (frequent ventricular ectopic beats of $10 \%$ or less of QRS complexes during 30 seconds, bigeminy/trigeminy, couplets, sustained or unsustained ventricular tachycardia during exercise or recovery). These criteria were defined in the study protocol and coded by the physician who conducted the
TABLE 1. Preoperative and surgical variables

\begin{tabular}{|c|c|c|c|}
\hline Variable & $\begin{array}{c}\text { EOA } / \text { BSA } \\
\leq 0.75 \mathrm{~cm}^{2} / \mathrm{m}^{2} \\
(\mathbf{n}=96 ; 61.1 \%)\end{array}$ & $\begin{array}{c}\text { EOA } / \text { BSA } \\
\geq 0.76 \mathrm{~cm}^{2} / \mathrm{m}^{2} \\
(\mathrm{n}=61 ; 38.9 \%)\end{array}$ & $\begin{array}{c}P \\
\text { value }\end{array}$ \\
\hline \multicolumn{4}{|l|}{ Preoperative variables } \\
\hline Age (y) & $67.8 \pm 7.5$ & $65.4 \pm 8.3$ & .06 \\
\hline Female sex & $33(31.7 \%)$ & $4(7.5 \%)$ & $<.001$ \\
\hline BSA $m^{2}$ & $1.88 \pm 0.14$ & $1.77 \pm 0.15$ & $<.001$ \\
\hline NYHA class III & $28(29.3 \%)$ & $10(18.9 \%)$ & .1 \\
\hline $\begin{array}{l}\text { Preoperative heart } \\
\text { failure* }\end{array}$ & $7(7.2 \%)$ & $4(6.5 \%)$ & 1 \\
\hline \multicolumn{4}{|l|}{ Surgical variables } \\
\hline $\begin{array}{l}\text { Urgent/emergency } \\
\text { operation }\end{array}$ & $10(9.6 \%)$ & $4(7.5 \%)$ & .3 \\
\hline Bicuspid aortic valve & $15(14.4 \%)$ & $7(11.3 \%)$ & .6 \\
\hline Pump time (min) & $87 \pm 12$ & $79 \pm 19$ & $<.001$ \\
\hline Crossclamp time & $62 \pm 11$ & $57 \pm 14$ & .013 \\
\hline \multicolumn{4}{|l|}{ Bioprosthetic valve } \\
\hline $19 \mathrm{~mm}$ & $40(100 \%)$ & 0 & \\
\hline $21 \mathrm{~mm}$ & $8(24.3 \%)$ & $25(75.7 \%)$ & $<.001$ \\
\hline \multicolumn{4}{|l|}{ Mechanical valve } \\
\hline $19 \mathrm{~mm}$ & $22(82.8 \%)$ & $5(17.2 \%)$ & $<.001$ \\
\hline $21 \mathrm{~mm}$ & $26(46.2 \%)$ & $31(56.4 \%)$ & .003 \\
\hline EOAi $\left(\mathrm{cm}^{2} / \mathrm{m}^{2}\right)$ & $0.65 \pm 0.08$ & $0.8 \pm 0.06$ & $<.001$ \\
\hline Operative mortality & $3(3.1 \%)$ & $2(3.2 \%)$ & .6 \\
\hline $\begin{array}{l}\text { Mean follow-up } \\
\text { time }(\mathrm{m})\end{array}$ & $84.1 \pm 32.1$ & $83.1 \pm 31.4$ & .8 \\
\hline
\end{tabular}

Values are expressed as mean \pm standard deviation or number (\%). BSA, Body surface area; NYHA, New York Heart Association; EOAi, indexed effective orifice area. *History of preoperative hospital admission for heart failure.

examination. Five patients had pre-existing atrial fibrillation and were excluded from arrhythmias analysis.

Morbidity and mortality were specified according to the Society of Thoracic Surgeons/American Association for Thoracic Surgery guidelines for reporting events after cardiac valve operations. ${ }^{24}$ According to these, we considered valve-related mortality and morbidity as deaths caused by structural valve deterioration, nonstructural deterioration, valve thrombosis, embolism, or bleeding. Operative mortality was defined as death within 30 days after operation. All patients who were reoperated on for any cause were excluded from final follow-up.

The hospital ethics committee approved this study, and individual informed consent was obtained from each patient included in the study.

\section{Surgical Technique}

All surgical procedures were performed by the same surgeon. The surgical approach consisted in median sternotomy, hollow-fiber oxygenators, and roller pumps. In all cases, the ascending aorta and right atrium were cannulated. Pump flow was kept at about $2.5 \mathrm{~L} \cdot \mathrm{min}^{-1} \cdot \mathrm{m}^{-2}$ and the arterial pressure at about $70 \mathrm{~mm} \mathrm{Hg}$. The myocardium was protected by intermittent anterograde cold blood cardioplegic solution infused into the ascending aorta. Retrograde cardioplegia was never used. Lowest core temperature varied from $33^{\circ} \mathrm{C}$ to $36^{\circ} \mathrm{C}$. The valves were excised through an oblique aortotomy and the prostheses were implanted with $2-0$ polyester mattress suture. Reinforcement with Teflon pledgets was not routinely used but was necessary in 11 patients. Mean aortic crossclamping time was $67.8 \pm 22.4$ minutes.

\section{End Points}

Late result of AVR with 19- or 21-mm prostheses was the first end point of this study. Secondary end points were as follows: (1) incidence of PPM 
TABLE 2. Types and sizes of prosthetic valves implanted and reference of effective orifice areas

\begin{tabular}{lcccc}
\hline \multicolumn{1}{c}{ Valve } & Size & $\begin{array}{c}\text { No. of } \\
\text { patients }\end{array}$ & $\begin{array}{c}\text { EOA* } \\
\left(\mathbf{c m}^{2}\right)\end{array}$ & References \\
\hline $\begin{array}{l}\text { Bioprosthetic valve } \\
\text { Medtronic Mosaic }\end{array}$ & $19 \mathrm{~mm}$ & $40(25.4 \%)$ & 1.2 & $2,12,16$ \\
& $21 \mathrm{~mm}$ & $33(21.1 \%)$ & 1.4 & $6,12,15$ \\
Mechanical valve & & & & \\
St Jude Medical & $19 \mathrm{~mm}$ & $7(4.5 \%)$ & 1.3 & 12,17 \\
$\quad$ Hemodynamic Plus & $21 \mathrm{~mm}$ & $19(12.2 \%)$ & 1.5 & 12,17 \\
St Jude Medical Regent & $19 \mathrm{~mm}$ & $20(12.7 \%)$ & 1.5 & 2,6 \\
& $21 \mathrm{~mm}$ & $26(16.5 \%)$ & 2.0 & 2,6 \\
Medtronic & $19 \mathrm{~mm}$ & $2(1.3 \%)$ & 1.0 & 12 \\
& $21 \mathrm{~mm}$ & $10(6.3 \%)$ & 1.3 & 12 \\
\hline
\end{tabular}

EOA, Effective orifice area. Medtronic, Inc, Minneapolis, Minn; St Jude Medical, Inc, St Paul, Minn. *EOA derived from values published in the literature.

and its impact on late results, (2) impact of abnormal echocardiographic features in AVR patients on late clinical status, and (3) identification of other issues as significant prognostic markers.

\section{Statistical Analysis}

Statistical analysis was performed by the SPSS program for Windows (SPSS, Inc, Chicago, Ill). Continuous data are presented as mean \pm standard deviation and categorical data as proportion. Comparison between continuous variables was done by the Student $t$ test for normally distributed features. The Mann-Whitney $U$ test was used for variables not normally distributed. Patient survival and freedom from valve-related complication were determined by the Kaplan-Meier method. Outcomes were compared by analysis of the $\chi^{2}$ test or the Fisher exact test as appropriate (categorical variables). Analysis of factors influencing early and late results was performed calculating the odds ratio (OR) with $95 \%$ confidence intervals (CI). All variables were analyzed in multivariate logistic regression models to assess the impact of each one on results. The variables tested in the models were as follows: (1) preoperativeage, gender, BSA, New York Heart Association functional class, and ILVM; (2) operative and postoperative-aortic crossclamp time, type and size of prosthesis implanted, EOAi, PPM, ILVM, MPGs, and arrhythmias. To assess the effect of PPM on variables, we developed a first model with PPM entered as a dichotomous variable (PPM: EOAi $\leq 0.75$ $\mathrm{cm}^{2} / \mathrm{m}^{2}$ vs no PPM) and then a second model with EOAi entered as a continuous variable.

\section{RESULTS}

Sixty-one percent of patients (96/157) had PPM. Mean EOAi was $0.69 \pm 0.05$ in the patients with PPM versus $0.88 \pm 0.1$ in patients with no PPM $(P<.001)$. Ten $(6.3 \%)$ patients had severe PPM (EOAi $\left.\leq 0.65 \mathrm{~cm}^{2} / \mathrm{m}^{2}\right)$. Univariate analysis of age, sex, and body mass revealed that patients with PPM were older, had higher prevalence of female sex, and larger BSA. Indeed, the only independent predictor of PPM was unfavorable EOA of the implanted prosthesis (Table 2). PPM occurred in $89.8 \%$ of patients $(62 / 69)$ with a $19-\mathrm{mm}$ prosthesis with a significant difference between mechanical and biological valves $(P<.01)$. When a $21-\mathrm{mm}$ valve was implanted, PPM occurred in $36.8 \%$ of patients $(43 / 88)$ with a prevalence not statistically significant in patients with a biological valve $(P=.2)$.
TABLE 3. Mortality

\begin{tabular}{lccr}
\hline \multicolumn{1}{c}{ Variables } & $\boldsymbol{P}$ value & Exp & CI 95\% \\
\hline $\begin{array}{l}\text { Cox survival analysis } \\
\text { Age } \geq 70 \text { y }\end{array}$ & & & \\
Logistic regression of variables & & 1.001 & $0.1-1.1$ \\
$\quad$ influencing perioperative death & & & \\
Age $\geq 70$ y & $<.001$ & 3.2 & $0.98-1.7$ \\
Female sex & $<.001$ & 1.8 & $1.2-2.7$ \\
NYHA class III & $<.001$ & 3.2 & $2.2-3.9$ \\
Preoperative heart failure* & $<.001$ & 3.5 & $2.4-4.2$ \\
\hline
\end{tabular}

Variables tested: Age, sex, New York Heart Association class, left ventricular ejection fraction, mean transprosthetic gradients, effective indexed orifice area less than 0.75 , indexed left ventricular mass, and size and type (mechanical or biological) of valve. CI, Confidence limits; NYHA, New York Heart Association. *History of preoperative hospital admission for heart failure.

Overall operative mortality was $3.1 \%(5 / 157)$. It was $3.1 \%(3 / 96)$ and $3.2 \%(2 / 61)$ for patients with and without mismatch, respectively $(P=.67)$. Multivariate predictors of operative mortality were age 70 years or older (OR 1.08, 95\% CI, 0.98-1.7), female sex (OR 1.8, 95\% CI, 1.22.7), preoperative New York Heart Association class III (OR 3.2, 95\% CI, 2.2-3.9), and history of preoperative hospital admission for heart failure (OR 3.5. 95\% CI, 2.4-4.2). No valve type or expression of valve size was identified as a risk factor of early mortality (Table 3 ).

Six patients were lost to follow-up. Redo operations were necessary in 5 patients with biological and in 2 with mechanical prostheses for malfunctions considered unrelated to PPM (hemolysis, 1; perivalvular leak, 1; annular fibrosis, 1; endocarditis, 1; and bioprosthesis degenerations, 3 ).

Late survival at follow-up was $92 \%(81 / 88)$ in the PPM group versus $92.1 \%$ (47/51) in patients without PPM $(P=.5)$. Three patients (1 with PPM and 2 without) died suddenly. Other causes of death were embolic stroke in 2, endocarditis in 2, cancer in 3, and bleeding in 1. PPM failed to be a significant predictor of related mortality that included

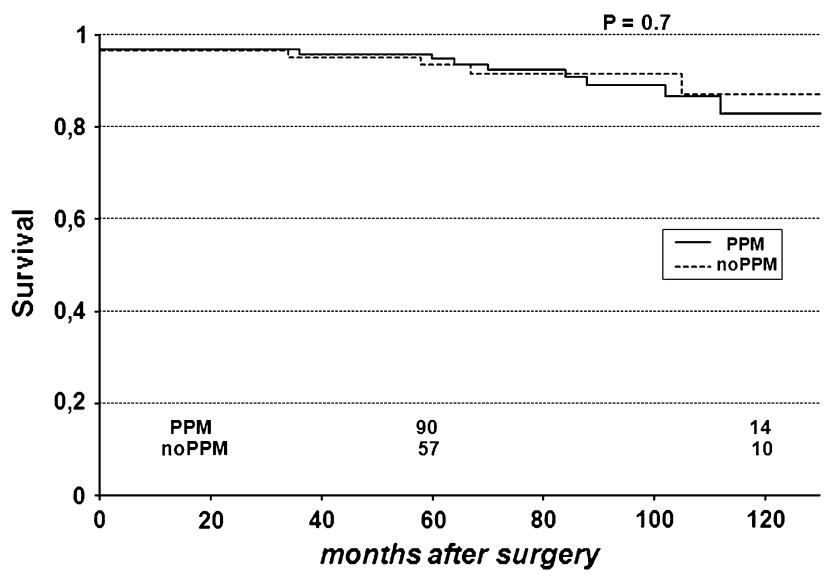

FIGURE 1. Actuarial survival curves, according to Kaplan-Meier method. Hospital mortality is included. PPM, Prosthesis-patient mismatch. 
TABLE 4. Preoperative and follow-up echocardiographic data

\begin{tabular}{|c|c|c|c|c|c|c|c|c|}
\hline & \multicolumn{2}{|c|}{ Preoperative } & \multicolumn{2}{|c|}{ First year } & \multicolumn{2}{|c|}{ Fourth year } & \multicolumn{2}{|c|}{ Final follow-up } \\
\hline & PPM & No PPM & PPM & No PPM & PPM & No PPM & PPM & No PPM \\
\hline LVEF (\%) & $54 \pm 8$ & $52 \pm 1$ & $58 \pm 1$ & $59 \pm 4$ & $60 \pm 6$ & $61 \pm 9$ & $61 \pm 3$ & $62 \pm 5$ \\
\hline MPG & $72 \pm 12$ & $71 \pm 13$ & $18 \pm 9$ & $16 \pm 5$ & $20 \pm 4$ & $19 \pm 2$ & $23 \pm 8$ & $21 \pm 9$ \\
\hline ILVM & $176 \pm 59$ & $178 \pm 95$ & $175 \pm 88$ & $172 \pm 72$ & $160 \pm 62$ & $151 \pm 44$ & $153 \pm 58$ & $148 \pm 53$ \\
\hline
\end{tabular}

Values are expressed as mean \pm standard deviation. $I L V M$, Indexed left ventricular mass; $L V E F$, left ventricular ejection fraction; $M P G$, mean prosthetic gradient; $P P M$, prosthesispatient mismatch.

mechanism of death totally unrelated . The only multivariate index of late mortality was age 70 years or older (OR 1.12, 95\% CI, 0.12-1.11) (Table 3). Actuarial survival curves, according to the Kaplan-Meier method, are reported in Figure 1.

At follow-up, 128 patients ( $81.5 \%$ of the original cohort) were evaluated between June and November 2007 in the outpatient department of our institution. Fifty percent of patients received $\beta$-blockers and $15 \%$ angiotensin-converting enzyme inhibitors; in $35 \%, \beta$-blockers and angiotensinconverting enzyme inhibitor therapy started after surgery.

Echocardiographic evaluations at rest evidenced an improvement of LV ejection fraction in both PPM and no PPM groups without statistically significant differences $(P=.3)$. One year after surgery, the MPGs were quite low in both groups without statistically significant differences $(P=.3)$. These values increased similarly at scheduled follow-up (Table 4).

Regression of ILVM values was impaired in both groups: $P=.0008$ in the PPM series and $P=.0002$ in the no PPM series. However, in the PPM group a trend of some postoperative reduction was observed even without statistical relevance. Correlation analysis related follow-up time $(P=.02)$, BSA $(P=.02)$, preoperative ILVM values $(P=.002)$, and late postoperative MPGs $(P=.009)$ with late postoperative ILVM values. However, multivariate analysis of ILVM revealed that only follow-up time (OR $2.5,95 \% \mathrm{CI}$, 1.3-4.7) and preoperative ILVM (OR 2.8, 95\% CI, 1.7-3.9) were associated with ILVM greater than $150 \mathrm{~g} /$ $\mathrm{m}^{2}$ in men and $125 \mathrm{~g} / \mathrm{m}^{2}$ in women at latest follow-up.

Elevated MGP values $(\geq 35 \mathrm{~mm} \mathrm{Hg})$ at rest were reported in $11.7 \%$ of patients $(15 / 128)$. They occurred in $11.1 \%$ of patients $(9 / 81)$ in the PPM group versus $6.8 \%$ of patients $(3 / 47)$ in the no PPM group $(P=.3)$. Patients with a mechanical valve had mostly low MPG values as compared with patients with bioprostheses of the same size $(P=.03)$. Echocardiographic evaluation under stress showed that elevated MPG index was strictly linked to reduced exercise capacity (OR 7.6, 95\% CI, 3.4-9.2; $P<.001$ ) (Figure 2). Multivariate analysis associated high ILVM values $\left(\geq 150 \mathrm{~g} / \mathrm{m}^{2}\right.$ in men and $\geq 125 \mathrm{~g} / \mathrm{m}^{2}$ in women) (OR $3.8,95 \%$ CI, 2.0-7.1; $P<.001$ ), female gender (OR 5.4, 95\% CI, 2.8-10.6; $P<.001$ ), and follow-up time of 85 months or more (OR $2.2,95 \%$ CI, $1.2-4.6 ; P=.006)$ with high MPGs at rest and under stress. Basically, in this present series, patients with abnormal gradients after surgery had LVM regression at follow-up equivalent to that of patients with low gradients. This suggests that MPGs did not influence LVM regression.

Stress evaluation showed reduced exercise tolerance in both PPM and no PPM groups. Patients without PPM achieved $59 \% \pm 14 \%$ PEC versus $56 \% \pm 18 \%$ in patients

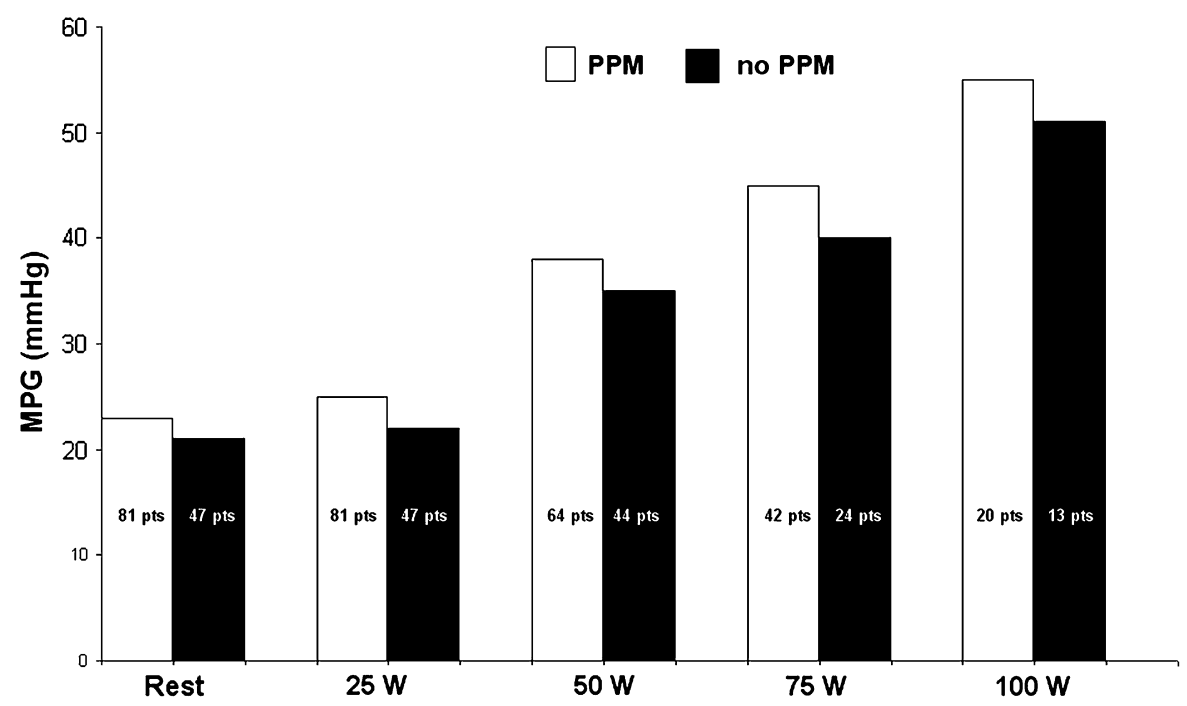

FIGURE 2. Mean pressure gradients $(M P G s)$ at rest and during exercise in patients with versus without prosthesis-patient mismatch (PPM). 


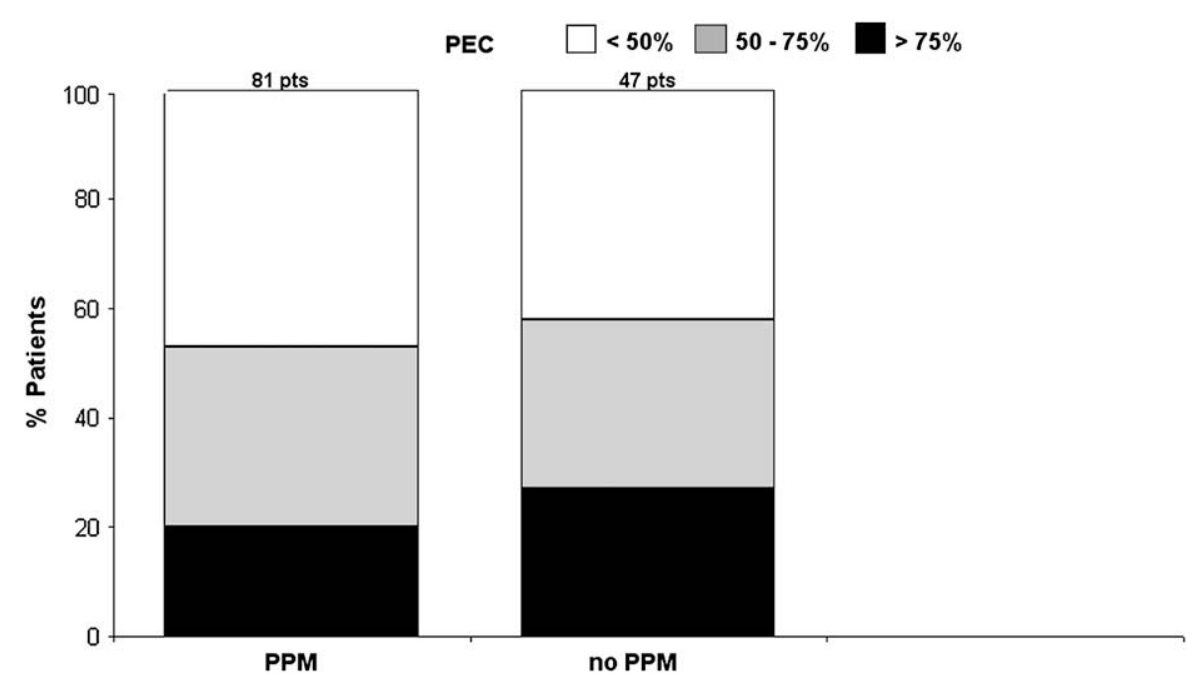

FIGURE 3. Distribution of percentage of the predicted exercise capacity $(P E C)$ in patients with and without prosthesis-patient mismatch $(P P M)$.

with PPM $(P=.08)$. The rate of patients achieving greater than $75 \%$ PEC was low in both groups: $23.4 \%(11 / 47)$ in no PPM versus $19.7 \%(16 / 81)$ in PPM groups (OR 1.2, 95\% CI, 0.6-2.6; $P=.6$ ) (Figure 3).

Arrhythmias occurred during exercise test in $33.3 \%$ of evaluated patients (41/123). During exercise $18(14.7 \%)$ patients had frequent ventricular ectopic beats, $14(11.3 \%)$ had bigeminism/trigeminism or couplets, $8(6.5 \%)$ unsustained ventricular tachycardia, and $1(0.8 \%)$ sustained ventricular tachycardia. During recovery from exercise, $12(9.7$ $\%)$ subjects had frequent ventricular ectopic beats, 14 $(11.4 \%)$ had bigeminism/trigeminism or couplets, and 5 (4\%) had unsustained ventricular tachycardia. Direct correlation between stress-induced arrhythmias and age greater than 65 years (OR 4.5, 95\% CI, 2.3-8.6; $P<.001$ ), MPG values of $50 \mathrm{~mm} \mathrm{Hg}$ or greater during exercise (OR 2.9, 95\% CI, 1.5-5.4; $P<.001$ ), high ILVM (OR 5,4, 95\% CI, 3.5-8.7; $P<.001$ ), 19-mm bioprosthesis (OR 3.2, 95\% CI 1.5-5.9; $P<.001)$, and BSA of $1.8 \mathrm{~m}^{2}$ or more (OR $4.8,95 \% \mathrm{CI}$, $2.8-7.7 ; P<.001)$ were assessed. However, multivariate analysis of arrhythmias revealed that only MPG values were independently predictive of arrhythmias: values of $50 \mathrm{~mm} \mathrm{Hg}$ or more after exercise test had $95 \%$ sensitivity and $72 \%$ specificity (area under the curve 0.80 ) for predicting arrhythmias.

\section{DISCUSSION}

PPM occurs when the EOA of an inserted prosthetic valve is inadequate for the recipient. ${ }^{1,9,12,14} \mathrm{PPM}$ is still a hot issue and its clinical relevance is not clear. Thus, new information is needed. PPM can result in persistent LV outflow tract obstruction with a high transvalvular gradient that increases LV work and reduces LVM regression. Surgical results are controversial. From currently available data, it seems likely that PPM has an impact on outcome after AVR in some patients but not in all. ${ }^{25}$ Many variables that can interfere with the occurrence of PPM have been reported. Therefore, they are more likely registered in patients with a larger body size, with AS as the predominant lesion (in correlation to the smaller annular size), and in advanced age (AS by degenerative calcification is by far the most prevalent lesion in older patients undergoing AVR). ${ }^{2}$

Our retrospective study enlisted a small but homogeneous population of patients carefully evaluated before and after surgery. All patients were followed up by a number of clinical, echocardiographic, and functional evaluations at last followup. Our results suggested that PPM, at a threshold of $0.75 \mathrm{~cm}^{2} / \mathrm{m}^{2}$, does not result in significant detrimental effects on overall long-term survival, freedom from heart failure, and LVM regression in our patients with pure AS and normal preoperative LV function. These findings are in conflict with other previous reports in which a larger number of AVRs were studied. However, these studies included patients with AS or aortic incompetence or both and patients with poor LV function. ${ }^{2-5,12,13}$ Patients with PPM and impaired LV systolic function at the time of AVR have a greater than twofold increase in the risk of late death and a fivefold increase in the cumulative incidence of heart failure by 3 years as compared with patients with normal LV function and no PPM. ${ }^{25,26}$ To avoid any misleading data, believing that AS has its own physiology, anatomy, and histology and, accordingly, that PPM can increase mortality and morbidity in patients with poor LV function, we selected only patients with pure AS and good LV ejection fraction. As largely reported, our results confirm that PPM incidence is high in the smaller prosthesis sizes. In our series it occurred in $61.1 \%$ of the whole population (92.5\% of patients with a $19-\mathrm{mm}$ prosthesis and $37.7 \%$ of patients with a 21-mm prosthesis). Patients with PPM were older, female, and had a larger BSA. By multivariate analysis, the only independent predictors of PPM were prosthesis size and its constructive characteristics. ${ }^{4,7}$ Operative and late 
mortality rates were low in our series, and only deaths totally unrelated to PPM were registered. No significant difference was observed in freedom from heart-related death or any major adverse cardiac events in patients with PPM as compared with others without PPM. Redo operations for bioprosthetic malfunction occurred in both groups without statistical difference.

This present study confirmed some interesting issues relating to echocardiographic long-term data. At 8 years' follow-up, LVM or the change in LVM indexed for BSA was not significantly different between PPM and no PPM patients. This finding may suggest potentially irreversible changes in the hypertrophied myocites and interstitium as a consequence of longstanding disease with impaired ventricular geometry and abnormal relaxation. ${ }^{27-29}$ The MPGs at rest were generally low and clinically insignificant regardless of PPM occurrence.

To satisfy the third end point, we investigated the impact of PPM on exercise capacity with regard to gender, age, and body weight ${ }^{30}$ : inasmuch as patients with heart valve disease have a reduced exercise capability compared with the healthy population, ${ }^{31}$ it is not surprising that only $25.4 \%$ of our patients achieved PEC of $75 \%$ regardless of the occurrence of PPM. Abnormal increment of the MPG (up to $50 \mathrm{~mm} \mathrm{Hg}$ ) values occurred in a large number of patients. Less exercise tolerance was registered in patients with higher LVMI and increased MPGs at stress. These results were not surprising considering that high transprosthetic gradients limit the increase of cardiac output during exercise similar to what happens in native AS and limit the capability of cardiac function to match the increasing metabolic demand during exercise.

However, the major finding of our study is the evidence of exercise-induced arrhythmias in one third of our patients. This incidence rises to $62.4 \%$ in the patients with significant increment of the MPG values under stress, even in patients with normal or moderate gradients at rest. In all patients, the increased duration of exercise was associated with more adverse events. Probably, the persistently elevated LVM, the impaired ventricular geometry, and the abnormal coronary flow reserve after AVR may predispose to the arrhythmias in patients with and without mismatch. ${ }^{31-34}$ This study confirms that, beyond occurrence of PPM, patients who underwent AVR with a small prostheses for pure AS have less exercise capacity and adds the important issue that they have significantly increased risk of arrhythmias. Intuitively, arrhythmias occurring during exercise should have an adverse impact on clinical outcome, but we failed to confirm this issue in our series. Our data, which we first describe, are very difficult to interpret. To our knowledge, studies that address the clinical long-term follow-up or the LV hypertrophy evaluations after AVR usually did not include details on these findings; equally, other studies of the impact of PPM on exercise capacity did not fully investigate modifications of prosthetic gradients under stress and occurrence of arrhythmias, especially in patients with a nearly normal gradient at rest. A possible explanation for these apparently conflicting results might be the protective effect of therapy with $\beta$-blockers and/or angiotensin-converting enzyme inhibitors received by $95 \%$ of our patients and withdrawn 5 days before exercise tests.

In conclusion, our results on a small population of patients cannot confirm with absolute statistical power whether PPM can or cannot be an independent predictor of early and late mortality; indeed, we believe that meaningful survival data can be obtained only from studies with a very large number of patients. However, our study confirms that PPM impairs LVM regression, but mainly it first shows that high LVM and increased transprosthetic gradient during exercise are strictly linked and have high sensitivity and specificity for predicting risk of arrhythmias. Postoperative extensive use of $\beta$-blockers and/or angiotensin-converting enzyme inhibitors may be useful in preventing these complications and improving early and late survival. Our study adds some new statement in the complex challenge of PPM, but further investigations will be necessary to confirm our preliminary observations in a larger sample of patients. Nevertheless, in our opinion, PPM may become a serious problem only in a particular risk population that needs a specific surgical strategy to minimize the risk of PPM.

\section{References}

1. Rahimtoola SH. The problem of valve prosthesis-patient mismatch. Circulation 1978;58:20-4

2. Pibarot F, Dumesnil JG. Hemodynamic and clinical impact of prosthesis-patient mismatch in the aortic valve position and its prevention. J Am Coll Cardiol. 2000 36:1131-41

3. Tasca G, Mhagna Z, Perotti S, Centurini PB, Sabatini T, Amaducci A, et al. Impact of prosthesis-patient mismatch on cardiac events and midterm mortality after aortic valve replacement in patients with pure aortic stenosis. Circulation. 2006; 113:570-6.

4. Blackstone EH, Cosgrove DM, Jamieson WRE, Birkmeyer NJ, Lemmer JH Jr, Miller DC, et al. Prosthesis size and long-term survival after aortic valve replacement. J Thorac Cardiovasc Surg. 2003;126:783-96.

5. Ruel M, Rubens FD, Master RG, Pipe AL, Bedard P, Hendry PJ, et al. Late incidence and predictor of persistent and recurrent heart failure in patients with aortic prosthetic valves. J Thorac Cardiovasc Surg. 2004;127:149-59.

6. Blais C, Dumesnil JG, Baillot R, Simard S, Doyle D, Pibarot P. Impact of valve prosthesis-patient mismatch on short-term mortality after aortic valve replacement. Circulation. 2003;108:983-8.

7. Hanayama N, Christakis GT, Mallidi HR, Joiner CD, Fremes SE, Morgan CD, et al. Patient prosthesis mismatch is rare after aortic valve replacement: valve size may be irrelevant. Ann Thorac Surg. 2002;73:1822-9.

8. He GW, Grunkemeier GL, Gately HR, Furnary AP, Starr A. Up to thirty-year survival after aortic valve replacement in the small aortic root. Ann Thorac Surg. 1995;59:1056-62.

9. David TE. Is prosthesis-patient mismatch a clinically relevant entity? Circulation. 2005;111:3186-7.

10. Medalion B, Blackstone EH, Lytle BW, White J, Arnold JH, Cosgrove DM. Aortic valve replacement: is the aortic valve size important? J Thorac Cardiovasc Surg. 2000;119:963-74.

11. Fuster RG, Montero Agundo JA, Albarova OG, Sos FH, Lopez SC, Codoner MB et al. Patient-prosthesis mismatch in aortic valve replacement: really tolerable? Eur J Cardiothorac Surg. 2005;27:441-9.

12. Pibarot P, Dumesnil J. Patient-prosthesis mismatch and the predictive use of in dexed effective orifice area: is it relevant? Cardiac Surg Today. 2003;1:43-51.

13. Pibarot P, Dumesnil JG, Cartier PC, Metras J, Lemieux MD. Patient-prosthesis mismatch can be predicted at the time of operation. Ann Thorac Surg. 2001;71: 265-8. 
14. Rahimtoola SH. Valve prosthesis-patient mismatch: an update. J Heart Valve Dis. 1998;7:207-10.

15. Florath I, Albert A, Rosendahl U, Ennker IC, Ennker J. Impact of valve prosthesispatient mismatch estimated by echocardiographic-determined effective orifice area on long-term outcome after aortic valve replacement. Am Heart J. 2007; 155: 135-42.

16. Cohn HL. Bioprosthetic aortic valve replacement: stented pericardial and porcine valve. In: Cardiac surgery in the adult. Chapter 34. 3rd ed. New York: McGrawHill; 2008. Table 34/10.

17. Mohty-Echahidi D, Malouf JF, Girard SE, Shaff HV, Grill DE, EnriquezSarano ME, et al. Impact of prosthesis-patient mismatch on long-term survival in patients with small St Jude Medical mechanical prostheses in the aortic position. Circulation. 2006;113:420-6.

18. Pibarot P, Dumesnil JG, Lamieux M, Cartier P, Matras J, Durand LG. Impact of prosthesis-patients mismatch on hemodynamic and symptomatic status, morbidity and mortality after aortic valve replacement with a prosthetic heart valve. J Heart Valve Dis. 1998;7:211-8.

19. Rao V, Jamieson WRE, Ivanov J, Armstrong S, David TE. Prosthesis-patient mismatch affects survival after aortic valve replacement. Circulation. 2000(19 Suppl 3); 102:III5-9.

20. Levy D, Savage DD, Garrison RG, Andersson KM, Kennel WB, Castelli WP. Echocardiographic criteria for left ventricular hypertrophy: the Framingham heart study. Am J Cardiol. 1987;59:956-60.

21. Shiller NB, Shah PM, Crawford M, De Maria A, Devereux R, Feigenbaum H, et al. Recommendations for quantitation of the left ventricle by two dimensional echocardiography. J Am Soc Echocardiogr. 1989;2:358-67.

22. ACC/AHA/ESC 2006 Guidelines for management of patients with ventricular arrhythmias. Circulation. 2006;114:1088-132.

23. Frolkis JP, Potier CE, Blackstone EH, Lauer MS. Frequent ventricular ectopy after exercise as a predictor of death. $N$ Engl J Med. 2003;348:781-90.

24. Edmunds LH, Clark RE, Cohn LH, Grunkemeier GL, Miller DC, Weisel RD. Guidelines for reporting morbidity and mortality after cardiac valvular operations. Ann Thorac Surg. 1996;62:932-5.
25. Ruel M, Al-Faleh H, KuliK A, Chan KL, Mesana TG, Burwash IG. Patientprosthesis mismatch after aortic replacement predominantly affects patients with pre-existing left ventricular dysfunction: effect an survival, freedom from heart failure, and left ventricular mass regression. $J$ Thorac Cardiovasc Surg. 2006;131:1036-44.

26. Connolly HM, Oh JK, Schaff HV, Roger VL, Osborn SL, Hodge DO, et al. Severe aortic stenosis with low transvalvular gradient and severe left ventricular dysfunction: result of aortic valve replacement in 52 patients. Circulation. 2000;101: 1940-6.

27. Devereux RB, de Simone G, Ganau A, Roman MJ. Left ventricular hypertrophy and geometric remodeling in hypertension: stimuli, functional consequences and prognostic implications. J Hypertens Suppl. 1994;12(Suppl S):S117-27.

28. Cuspidi C, Lonati L, Sampieri L, Leonetti G, Zanchetti A. Physiological versus pathological hypertrophy: the athlete and hypertensive. Adv Exp Med Biol. 1997;432:145-58

29. Di Bello V, Pedrinelli R, Giorgi D, Bertini A, Talarico G, Caputo MT, et al. Ultrasonic videodensitometric analysis of two different models of left ventricular hypertrophy: athlete's heart and hypertension. Hypertension. 1997;29: 937-44.

30. Woo JS, Derlet C, Stratton JR, Levy WC. The influence of age, gender, and training on exercise efficiency. J Am Coll Cardiol. 2006;47:1049-57.

31. Bleiziffer S, Eichinger WB, Hettich I, Ruzicka D, Wattke M, Bauemschmitt R, et al. Impact of patient-prosthesis mismatch on exercise capability in patients after bioprosthetic aortic valve replacement. Heart. 2008;94:637-41.

32. Rajappan K, Rimoldi OE, Camici PG, Bellewnger NG, Pennell DJ, Sheridan DJ. Functional changes in coronary microcirculation after valve replacement in patients with aortic stenosis. Circulation. 2003;107:3170-5.

33. Rajappan K, Rimoldi OE, Dutka DP, Ariff B, Peunel DJ, Sheridan DJ, et al. Factors influencing coronary microcirculatory function in patients with aortic stenosis after aortic valve replacement. Circulation. 2002;106:II-640.

34. Nemes A, Forster T, Csanady M. Decreased aortic distensibility and coronary flow velocity reserve in patients with significant aortic valve stenosis with normal epicardial coronary arteries. J Heart Valve Dis. 2004;13:567-73. 